\title{
Obstructive sleep apnea and ischemic stroke: a risk assessment
}

\section{Tomoyuki Kawada ${ }^{1}$}

Received: 4 March 2019 / Accepted: 22 May 2019 / Published online: 27 May 2019

(C) Fondazione Società Italiana di Neurologia 2019

Dear Editor,

I have read the article entitled "Stroke during sleep and obstructive sleep apnea: there is a link" by Mohammad et al. with interest [1]. The authors conducted a case-control study to investigate the association between obstructive sleep apnea (OSA) and ischemic stroke during sleep, which was referred to as "wake-up stroke (WUS)." The Berlin Questionnaire was used for the analysis. By logistic regression analysis, adjusted odds ratio (OR) (95\% confidence interval [CI]) of OSA for WUS was 3.25 (1.397-8.38). I have some concerns with regard to this study.

First, conditional logistic regression analysis can be adopted for a case-control study. Assuming that the authors could not conduct strict matching procedures between the test and controls, an unconditional model would also be applicable for the analysis. Since OSA diagnosis was not made using a physiological method, its validity should be kept in mind. Additionally, the time at which the Berlin Questionnaire was administered is also important for the analysis. Furthermore, the number of WUS events was 40 ; risk estimation by multivariate analysis would become unstable when the number of independent variables increases [2,3].

Second, Kim et al. examined the causal relationship between the preexisting OSA symptoms and the onset of acute ischemic stroke by using the Berlin Questionnaire [4]. The adjusted OR (95\% CI) of OSA for WUS was 2.055 (1.0354.083). They conducted a prospective study and have recommended treating OSA to prevent WUS.

Finally, Xiao et al. conducted a meta-analysis to verify the association between WUS and sleep-disordered breathing (SDB) [5]. Considering the mechanism of association, causal direction from WUS to SDB seems improbable; there was no significant association in calculating standardized mean difference of the Apnea-Hypopnea Index. However, a significant increase in the association was observed when the severe sleep apnea was selected for calculating pooled OR of WUS. Nonetheless, further studies are needed to evaluate the association between OSA and WUS.

\section{Compliance with ethical standards}

Conflict of interest The author declares that there is no conflict of interest.

\section{References}

1. Mohammad Y, Almutlaq A, Al-Ruwaita A, Aldrees A, Alsubaie A, Al-Hussain F (2019) Stroke during sleep and obstructive sleep apnea: there is a link. Neurol Sci 40:1001-1005. https://doi.org/10. 1007/s10072-019-03753-2

2. Peduzzi P, Concato J, Kemper E, Holford TR, Feinstein AR (1996) A simulation study of the number of events per variable in logistic regression analysis. J Clin Epidemiol 49:1373-1379

3. Novikov I, Fund N, Freedman LS (2010) A modified approach to estimating sample size for simple logistic regression with one continuous covariate. Stat Med 29:97-107

4. Kim JS, Kim S, Lee SH, Lee HY, Lee SY, Im KB (2018) Increased risk of ischemic stroke during sleep in apneic patients. J Clin Neurol 14:174-178

5. Xiao Z, Xie M, You Y, Wu H, Zhou G, Li M (2018) Wake-up stroke and sleep-disordered breathing: a meta-analysis of current studies. J Neurol 265:1288-1294

Publisher's note Springer Nature remains neutral with regard to jurisdictional claims in published maps and institutional affiliations.

Tomoyuki Kawada

kawada@nms.ac.jp

1 Department of Hygiene and Public Health, Nippon Medical School, 1-1-5 Sendagi, Bunkyo-Ku, Tokyo 113-8602, Japan 